\title{
Temperature Difference Effect between Two Samples Ends on the Inception of Thermal Sensitivity
}

\author{
Ridha Hameed Majeed
}

Kerbala technical institute, Alfurat Al-Awsat technical university, 56001, kerbala, Iraq

inkr.red@atu.edu.iq

\begin{tabular}{|l|l|l|}
\hline Submission date:- 4/4/2019 & Acceptance date:- 5/5/2019 & Publication date:-18/5/2019 \\
\hline
\end{tabular}

\begin{abstract}
This paper examined the effect of the difference between the temperature of the two end of the body exposed to transient conduction heat transfer on the inception of thermal sensitivity and at different distances from the hot end of the sample. The study was based on the selection of a sample with a length of $15 \mathrm{~cm}$ and a fixed height of $1 \mathrm{~cm}$. Four materials with different thermal properties were selected. One end of the model was exposed to three different temperatures $(75,125$, and 175$){ }^{\circ} \mathrm{C}$. The other end of the sample was placed under a convection heat transfer at $25^{\circ} \mathrm{C}$. To adopt an inception indicator of thermal sensitivity of the sample when exposed to transient heat transfer, $(26){ }^{\circ} \mathrm{C}$ was used because it is the nearest temperature to the initial condition of the sample. Four points were selected on different distance from hot end along the sample. The hot end temperature was also adopted as an indicator to measure the effect of the temperature difference for two body ends as the other end is subject to constant transient heat transfer. Determine the effect of the temperature difference between two body ends exposed to transient heat transfer on the inception of thermal sensitivity is study target.

The results of this study showed the reverse effect of the temperature difference between two body ends exposed to transient heat transfer on the inception of thermal sensitivity, this effect increases by increasing the distance from hot sample end and depressing of thermal diffusivity. The results also showed that the values of the Thermal sensitivity inception ranged between (0.43-17845) seconds according to the distance from the hot end, its temperature, and the thermal diffusivity of sample materials for each case.
\end{abstract}

Keywords: Transient heat transfer, Inception of thermal sensitivity, Thermal diffusivity $(\alpha)$, Hot end temperature, Distance from hot end (x).

\section{Nomenclature}

$\mathrm{D}$

T. S.I

$\mathrm{T}$

$\alpha$

K

$\rho$

$\mathrm{C}$

$\mathrm{X}$

$\mathrm{t}$
Distance from the hot end (m)

Thermal sensitivity inception (second)

hot sample end temperature $\left({ }^{\circ} \mathrm{C}\right)$

thermal diffusivity $\left(\mathrm{m}^{2} / \mathrm{sec}\right)$

thermal conductivity $\left(\mathrm{W} / \mathrm{m} .{ }^{\circ} \mathrm{C}\right)$

Density $\left(\mathrm{Kg} / \mathrm{m}^{3}\right)$

Specific heat $\left(\mathrm{J} / \mathrm{Kg} .{ }^{\circ} \mathrm{C}\right)$

distance between two nodes (m)

time (second) 


\section{1-Introduction}

Because of the difficulty of providing tools and conditions to measuring transient heat transfer. Therefore, we note the number of researches implemented to solve this problem mathematically much more than those that deal with the same problem in practice

This work was interested to studying the variables affecting the thermal sensitivity inception (T. S.I) for the model of transient heat transfer exhibition.

Many of theoretical research's, which dealt with the study of unstable heat transfer problems.

The results of one research showed that increasing the temperature difference between ends of any sample exposed to transient heat transfer would increase the sample temperature at steady state case and reduce the time needed to reach steady state case, but the thermal diffusivity effect of any material was the opposite of the temperature difference [1]. Additional study showed the effect of sample length was very small on the thermal initiation time for deferent thermal diffusivity materials [2]. A new search presentation that increasing the thermal diffusivity of any sample exposed to transient heat transfer would decrease the sample temperature at steady state case and increase the time needed to reach steady state case [3].

By the steady-state 1-D Fourier heat conduction theory under Dirichlet's boundary conditions, In one research was conducted thermal analyses of radially graded were done theoretically for an infinite cylindrical and a spherical vessel. The distribution of temperature and heat flow in the radial direction given by the mathematical analysis solution of differential equations as a closed model. The results obtained may be used directly in some thermal Applications and optimization [4]. By a previous study a mathematical solution for anisotropic unstable heat conduction were applied in a truncated composite conical shell. Accurate solution of equation was obtain by means of an integral transform in angular direction and the transferred heat equation was solve using method of variables separation. The analytical results were compared with the solution of the different method of the second-order to confirm the validity of it. That solution has industrial applications [5]. Anisotropic conductive heat transfer in a composite cylindrical shell was solve by an exact analytical method. Through mathematical analysis, temperature distribution can be observed in axial and transient directions. Variables separation method and Fourier series were adopted to determine unknown coefficients in the final solution. The obtained analytical results correspond well with the solved numerical results, but it is agree with the few pertinent industrial cases [6]. A new study has simplified the MTPS as a multi-layered plate using a onedimensional unstable heat transfer analysis across the wall. A new analytical approximation method based on the separation of variables and orthogonal expansion technique was used to predict the temperature, taking into account the thermal properties of the materials that depend on the temperature. The method adopts a numerical solution that fully divides the heat transfer process into a number of selected time steps to solve the problem of changing boundary conditions over time [7].

The method of separating variables was adopted to obtain the temperature distribution through a multi-layered cylinder wall during unstable heat transfer. This solution was applied for any set of boundary conditions. This technique can be used to find temperature distribution over a multi-layer with zero internal radius[8]. Two-dimensional thermal conductivity problems was solve by transforming problem geometry into gradient border coordinates including radial and circumferential coordinates using SBFEM. In analyzing the steady state and transient heat transfer problem the matrix variables calculated from eigenvalue are used to find temperature distribution along the body. SBFEM considered as a simple way for solution the heat conduction problems numerically with non-homogeneous and anisotropic media [9]. Another study offers analytical solutions for the thermal conductivity problems of the limited dimensional media. The applicable boundary conditions are either thermal isolation or isothermal. Fourier transform technique was used with image method as analytical solutions to find both temperature and heat flow throughout the body [10]. In new study, models were propose for transient heat analysis of a multi-layer tube with active heating. Two-points Hermite approximations for integrals procedure was use to improved lumped models in this study. The coupled system of ordinary differential equations for average temperatures in the solids and bulk temperature of the fluid at each point along the pipeline was solved by using an Ordinary Differential Equations [11].

In order to achieve the best match between the mathematical solution and the practical results in this paper, the appropriate mechanism to determine the number of optimal partitions of the wall thickness was discussed, as well as the possible accuracy of the speed of cooling, in addition to the optimal values of Fourier number. In the practical side, thermal flow was studied in the unstable state on a wall made 
up of two panels of wood, including extended and medium density polystyrene foam. The results showed that the use of layers with equal thermal diffusion values obtains a uniform distribution of temperature across the wall [12]. Another paper aims to provide very accurate analytical solutions when using small values of time to calculate transient heat in two-dimensional Cartesian finite bodies. Simple 1-dimension Cartesian finite body's solutions used to obtain very accurate temperature and heat flow values at any point in the body to avoid long integration [13]. An accurate analytical solution for unsteady state conduction heat transfer by in multilayer cylindrical composite layers was provided through a new study. Was the solution is suitable for more general linear boundary conditions consisting of thermal conductivity and radiative convection. To use the frequency instead of time domain in solution, Laplace transformation was used. A suitable Fourier transformation was derived using the Storm-Liouville theory. The mathematical results were compared with practical examples to investigate the ability of the mathematical solution to solve a wide range of steady and transient heat transfer problems [14].Unsteady state heat transfer was studied through fins of different shapes. Thermal conductivity and heat transfer coefficients were assumed associated with temperature. The results of this assumption gave a nonlinear relationship. The original partial differential equation has been solved numerically. Fin shape and the heat transfer coefficient on the temperature distribution were studied[15]. The problem of transient conduction heat transfer by through a three-dimensional wall was solved by employing eigenfunctions. Its results were compared with the solution that obtained from the numerical solution of finite difference. Depending on the solution results, a formula was developed to solve heat transfer across a wall containing n-layers [16].

Previous studies dealt the practical and theoretical methods for transient heat transfer during solid bodies and discussed the variables affecting the results of that transport. This research focused on the study of a number of variables affecting in solid object exposed to transient heat transfer in inception of thermal sensitivity, across a different points along that body. The most important of which is the effect of temperature difference between its two sides of body. Ansys program was use in this study.

\section{2-Research proceedings}

Among the many methods used to solve the problem of transient heat transfer by conduction, the ANSYS-14 program is one of the methods that gives a preliminary approximation of the practical results compared to other methods [17, eq. (1)].

$$
K_{n} \frac{\partial^{2} T}{\partial x^{2}}=\rho_{n} C_{n} \frac{\partial T}{\partial t}
$$

To study the effect of the change in temperature of the hot side of sample exposed to heat transfer at transient case on the inception of thermal sensitivity(I.T.S) of its and at different distances from the hot side, the ANSYS-14 program was used for this purpose. Four materials with different thermal properties were chosen (Aluminum, Glass-Fiber Quilt, Expanded Polystyrene and Hardboard (Standard)). A parallelogram sample with dimensions (length $=15 \mathrm{~cm}$, height $=1 \mathrm{~cm}$ ) was used in the search. One aspect of the sample was exposed to three different temperatures $\left(75,125\right.$ and $\left.175^{\circ} \mathrm{C}\right)$, while the other side of the sample was exposed to convection heat transfer at $25^{\circ} \mathrm{C}$. It was assumed that the heat transfer was only through the sample length (one dimension), there was no heat generation in the sample, and it was assumed that the other aspects of the sample were thermally isolated.

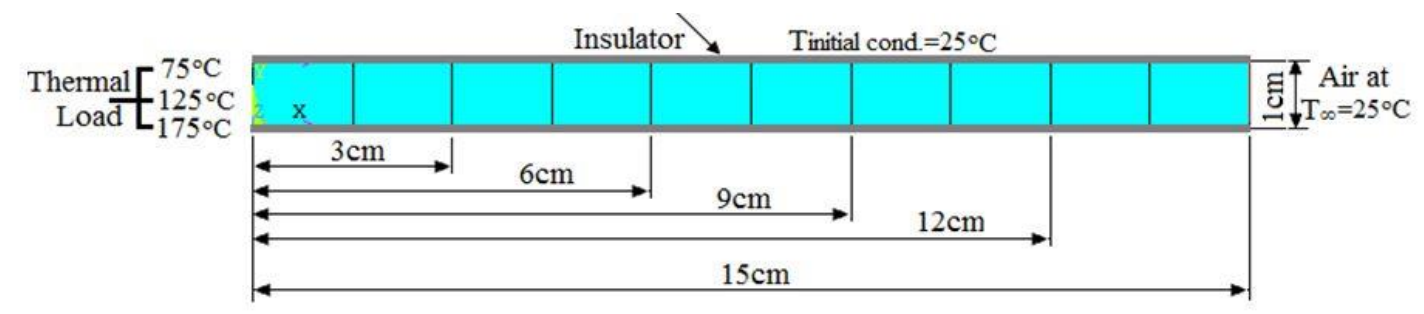

Figure (1) Specifications of the research sample 
Table (1) thermal properties of materials and thermal conditions $[18,19]$

\begin{tabular}{|c|c|c|c|c|}
\hline & Aluminum & Glass-Fiber Quilt, & Expanded Polystyrene & $\begin{array}{c}\text { Hardboard } \\
\text { (Standard })\end{array}$ \\
\hline $\mathrm{K}\left(\mathrm{W} / \mathrm{m}^{\circ}{ }^{\circ} \mathrm{C}\right)$ & 160 & 0.04 & 0.035 & 0.13 \\
\hline$\rho\left(\mathrm{Kg} / \mathrm{m}^{3}\right)$ & 2800 & 12 & 29 & 900 \\
\hline $\mathrm{Cp}\left(\mathrm{J} / \mathrm{Kg} .{ }^{\circ} \mathrm{C}\right)$ & 896 & 840 & 1213 & 2000 \\
\hline$\alpha\left(\mathrm{m}^{2} / \mathrm{sec}\right)$ & $6.38 \mathrm{E}-5$ & $3.97 \mathrm{E}-6$ & $9.95 \mathrm{E}-7$ & $7.22 \mathrm{E}-8$ \\
\hline
\end{tabular}

Table (2) Thermal conditions and constant of ANSYS-14

\begin{tabular}{|c|c|c|c|c|}
\hline \multirow{2}{*}{\multicolumn{2}{|c|}{$\begin{array}{l}\text { Convection Heat transfer coefficient } \backslash \\
\text { right side }\left(\mathrm{h}_{\text {conv }}\right) \\
\text { Left side temperature }\end{array}$}} & \multicolumn{3}{|l|}{$10 \mathrm{~W} / \mathrm{m}^{2} .^{\circ} \mathrm{C}$} \\
\hline & & $75^{\circ} \mathrm{C}$ & $125^{\circ} \mathrm{C}$ & $175^{\circ} \mathrm{C}$ \\
\hline \multicolumn{3}{|c|}{ initial condition temperature of sample ( $\left.\mathrm{T}_{\text {initial cond. }}\right)$} & \multicolumn{2}{|l|}{$25^{\circ} \mathrm{C}$} \\
\hline \multicolumn{3}{|l|}{ Element edge length } & \multicolumn{2}{|c|}{$0.001 \mathrm{~m}$ (mesh=fine) } \\
\hline \multicolumn{3}{|l|}{ Preferences for filtering } & \multicolumn{2}{|c|}{ Thermal } \\
\hline \multicolumn{3}{|l|}{ Type of analysis } & \multicolumn{2}{|l|}{ Transient } \\
\hline materials & Aluminum, & Glass-Fiber Quilt, & $\begin{array}{l}\text { Expanded } \\
\text { Polystyrene }\end{array}$ & $\begin{array}{l}\text { Hardboard } \\
\text { (Standard) }\end{array}$ \\
\hline $\begin{array}{lll}\begin{array}{l}\text { Applied } \\
\text { (sec) }\end{array} & \text { time load } \\
\end{array}$ & 25 & 300 & 1500 & 20000 \\
\hline Time step size (sec) & 0.01 & 0.1 & 1 & 5 \\
\hline
\end{tabular}
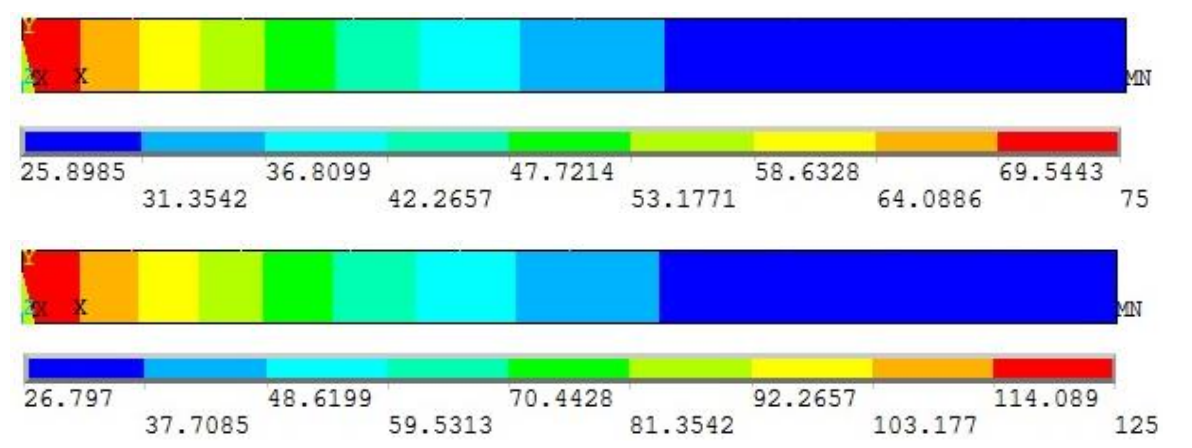

$\mathrm{T}=125^{\circ} \mathrm{C}$

Aluminum

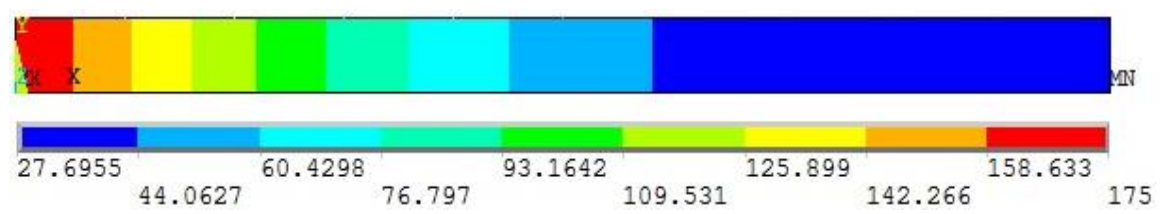

$\mathrm{T}=175^{\circ} \mathrm{C}$

Aluminum

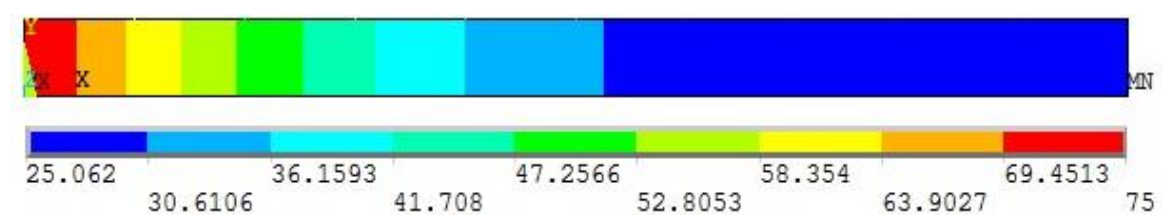

$\mathrm{T}=75^{\circ} \mathrm{C}$

Glass-Fiber

Quilt

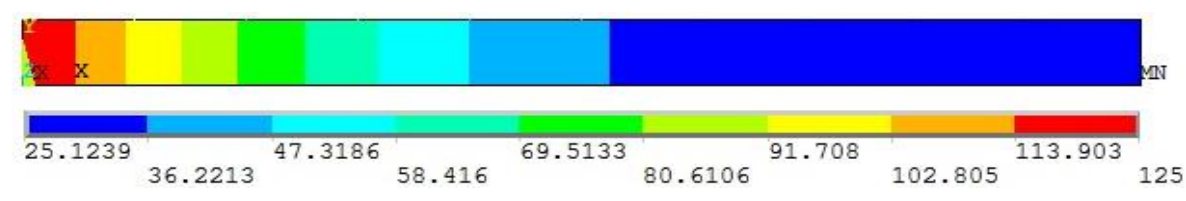

$\mathrm{T}=125^{\circ} \mathrm{C}$

Glass-Fiber Quilt

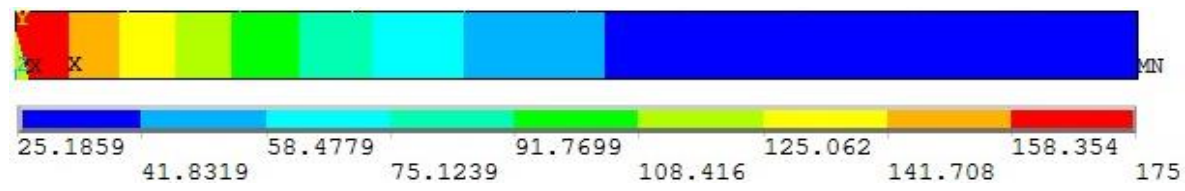

$\mathrm{T}=175^{\circ} \mathrm{C}$

Glass-Fiber Quilt 


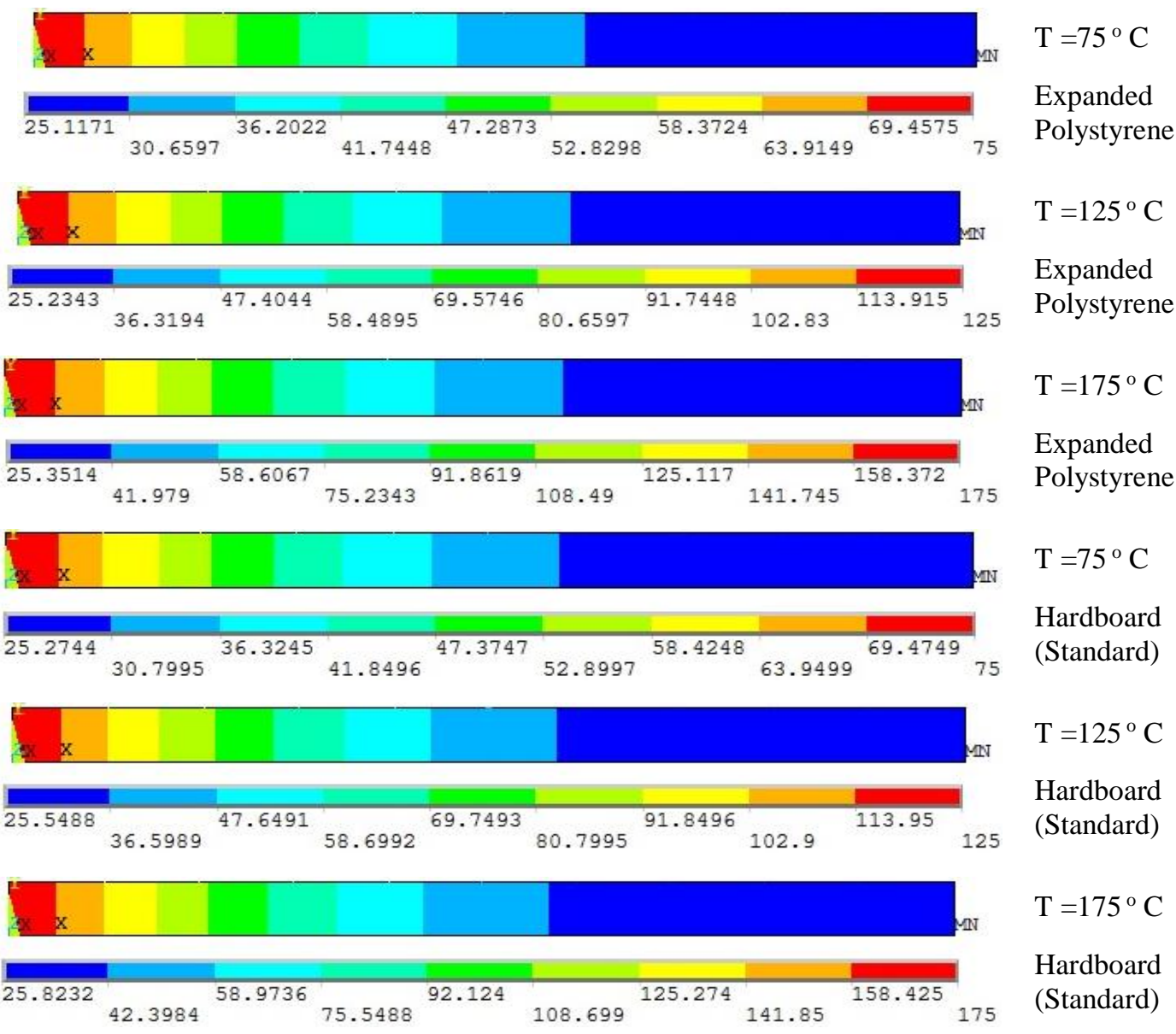

Figure(2) Images from Ansys Program for Temperature Distribution of Samples

\section{3-Results Discussion:}

There are many factors were effecting on the heat transfer for anybody exposed to thermal load in transient case such as the difference in temperatures between the sides of body which represent the thermal force to heat transfer and thermal properties of material which describe by thermal diffusivity that represent the ability of this material to heat conduction. Additional factor is the heat transfer distance where it's proportional inversely with heat transfer. Figure 3 illustrated the affecting variables on thermal sensitivity inception (T. S.I).

When other variables are constant, with decreasing the thermal diffusivity, the Thermal sensitivity inception (T. S.I) will increases. The affecting of hot side temperature to the time of inception of thermal sensitivity temperature inversely. While the relationship between the amount of distance from the hot side with the Thermal sensitivity inception (T. S.I) is positive.

Through the shapes and values shown in each case, we observe that the thermal diffusivity has an influence on the Thermal sensitivity inception (T. S.I) much more than the effect of the distance from the heating source. 
The hot side temperature, which expresses the thermal driving force, did not show its effect on the Thermal sensitivity inception (T. S.I) at the high values of thermal diffusivity, but its effect was clearly shown at the low thermal diffusivity values.

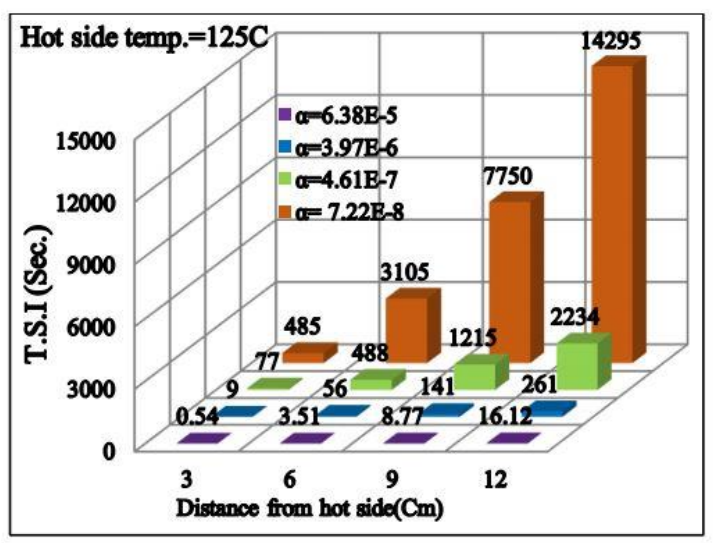

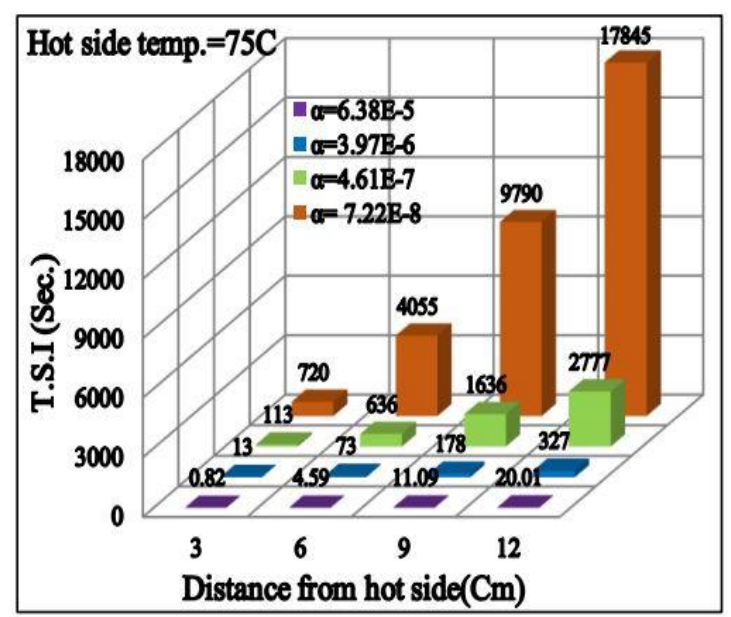

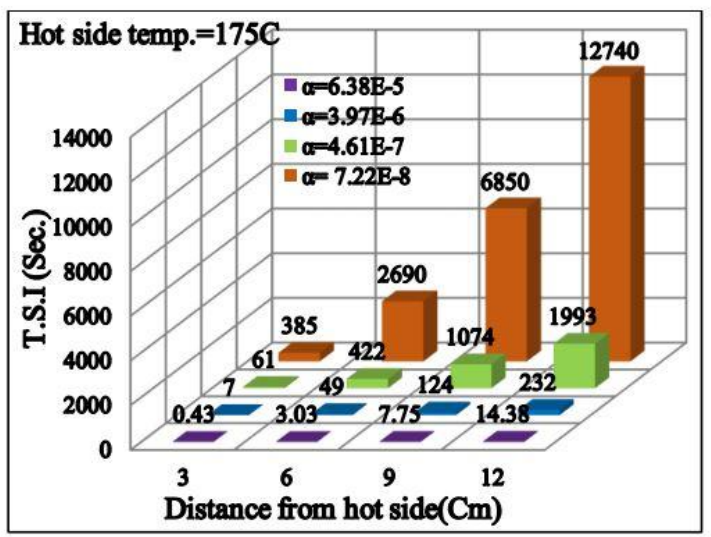

Figure 3. Effect of distance from hot side of sample on the inception of thermal sensitivity

Figure. 4 shows the effect of thermal diffusivity on the Thermal sensitivity inception (T. S.I) when the distance from the heating source is constant with different values of hot side temperature.

Another observation, the increasing in hot side temperature has a slight effect on increasing the Thermal sensitivity inception (T. S.I), predominantly at the elevated values of thermal diffusivity, but this effect increases with a drop of thermal diffusivity values.
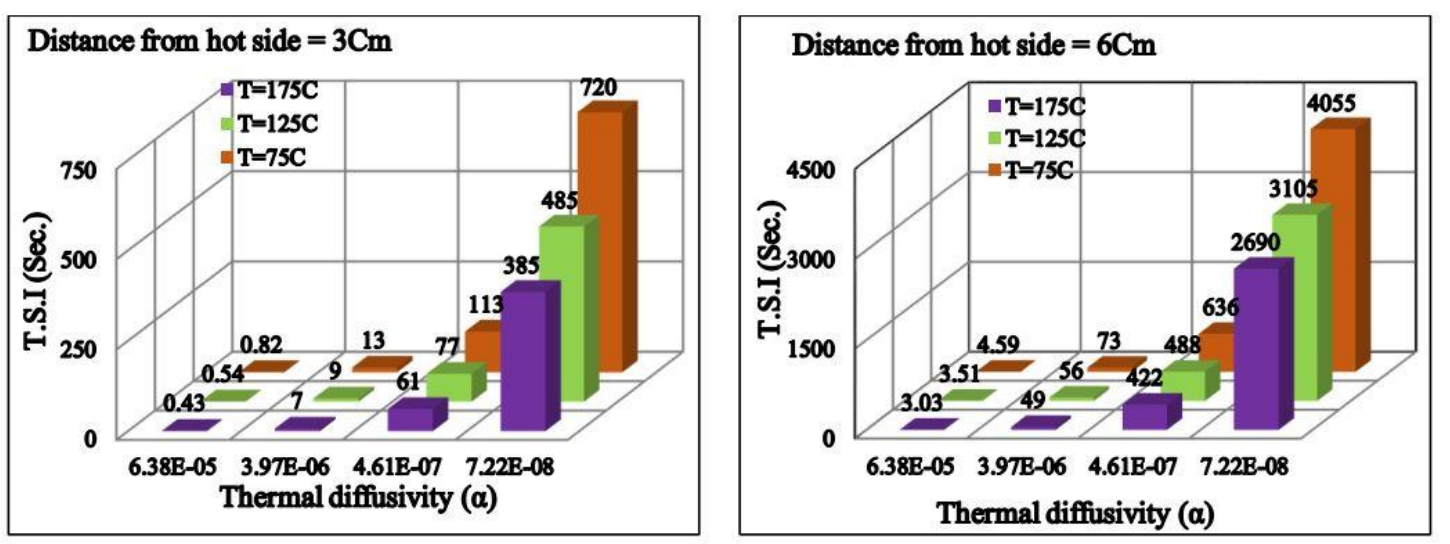

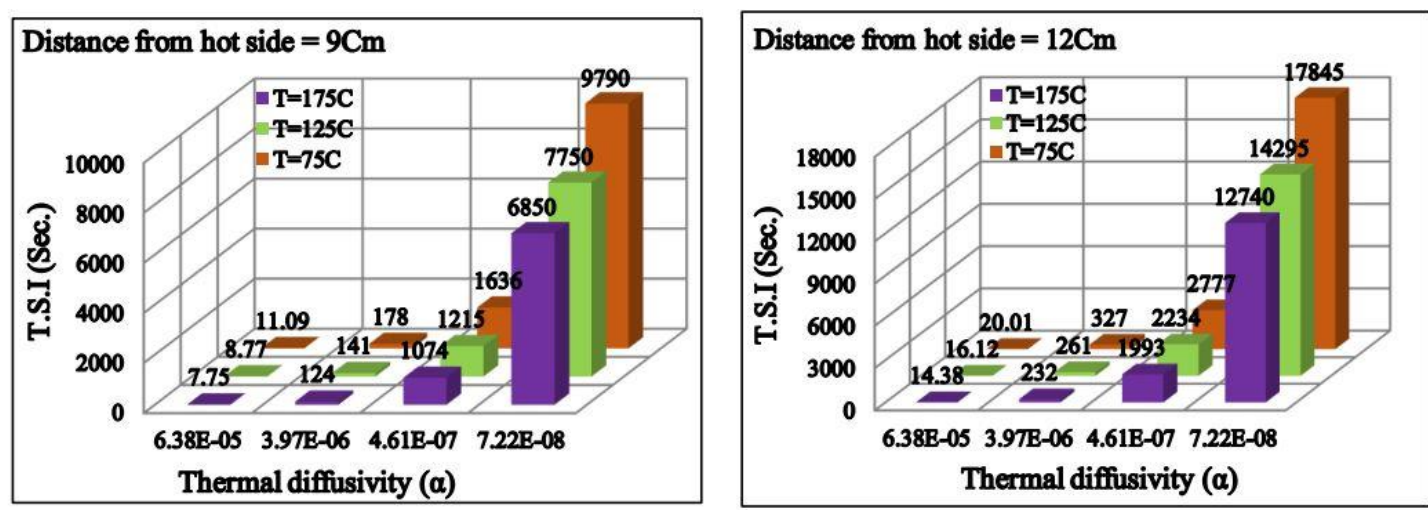

Figure 4. Effect thermal diffusivity on the inception of thermal sensitivity

From table 3. We can observe that the ratio between the Thermal sensitivity inception (T.S.I) at any thermal diffusivity to the Thermal sensitivity inception (T. S.I) at any other value of thermal diffusivity was be equivalent, And these ratio remain equalizes with change the distance from hot side and its temperature.

So we can form a general perception that is the ratio between (T. S.I) at any thermal diffusivity to the (T. S.I) at any other thermal diffusivity is equalizes to the inverse ratio between thermal diffusivity of the two cases.

$\frac{\text { (T.S.I)at } \alpha=3.97^{-6}}{\text { (T.S.I)at } \alpha=6.38^{-5}} \cong \frac{1}{\frac{3.97^{-6}}{6.38^{-5}}} \cong 16 \quad$ at any distance from hot side and its temperature.
$\frac{\text { (T.S.I)at } \alpha=4.61^{-7}}{\text { (T.S.I)at } \alpha=3.97^{-6}} \cong \frac{1}{\frac{4.61^{-7}}{3.97^{-6}}} \cong 9 \quad$ at any distance from hot side and its temperature.
$\frac{\text { (T.S.I)at } \alpha=7.22^{-8}}{\text { (T.S.I)at } \alpha=4.61^{-7}} \cong \frac{1}{\frac{7.22^{-8}}{4.61^{-7}}} \cong 6 \quad$ at any distance from hot side and its temperature.

From the data in a table 3 which obtained from the search results, we can conclude a general equation to describe the thermal behavior of materials in fig. 4.

When measuring the Thermal sensitivity inception (T. S.I) at any point of solid material exposed to transient heat transfer, we can know the Thermal sensitivity inception (T. S.I) of the other material at the same point by applying equation (2) on the assumption that the second material has the same dimensions and thermal conditions as the first material.

$$
\frac{(\text { T. S. I })_{\mathrm{A}}}{(\text { T. S. I })_{B}}=\frac{\alpha_{B}}{\alpha_{A}}
$$


Table (3) Results of inception of thermal sensitivity and the relative relationship between

\begin{tabular}{|c|c|c|c|c|c|c|c|c|c|c|}
\hline $\mathrm{A}$ & $\mathrm{B}$ & $\mathrm{C}$ & $\mathrm{D}$ & $\mathrm{E}$ & & & & & & \\
\hline & $\mathrm{X}=3 \mathrm{Cm}$ & $\mathrm{X}=6 \mathrm{Cm}$ & $\mathrm{X}=9 \mathrm{Cm}$ & $\mathrm{X}=12 \mathrm{Cm}$ & $\mathrm{C} / \mathrm{B}$ & $\mathrm{D} / \mathrm{C}$ & $\mathrm{E} / \mathrm{D}$ & $\mathrm{B}_{1} / \mathrm{C}_{1}$ & $\mathrm{C}_{1} / \mathrm{D}_{1}$ & $\mathrm{D}_{1} / \mathrm{E}_{1}$ \\
\hline $\mathbf{( 1 )}$ & $6.38 \mathrm{E}-05$ & $3.97 \mathrm{E}-06$ & $4.61 \mathrm{E}-07$ & $7.22 \mathrm{E}-08$ & 0.062 & 0.116 & 0.157 & 16 & 9 & 6 \\
\hline $\mathrm{T}=75^{\circ} \mathrm{C}$ & 0.82 & 13 & 113 & 720 & 15.85 & 8.69 & 6.37 & & & \\
\hline $\mathrm{T}=125^{\circ} \mathrm{C}$ & 0.54 & 9 & 77 & 485 & 16.67 & 8.56 & 6.30 & & & \\
\hline $\mathrm{T}=175^{\circ} \mathrm{C}$ & 0.43 & 7 & 61 & 385 & 16.28 & 8.71 & 6.31 & & & \\
\hline $\mathrm{T}=75^{\circ} \mathrm{C}$ & 4.59 & 73 & 636 & 4055 & 15.90 & 8.71 & 6.38 & & & \\
\hline $\mathrm{T}=125^{\circ} \mathrm{C}$ & 3.51 & 56 & 488 & 3105 & 15.95 & 8.71 & 6.36 & & & \\
\hline $\mathrm{T}=175^{\circ} \mathrm{C}$ & 3.03 & 49 & 422 & 2690 & 16.17 & 8.61 & 6.37 & & & \\
\hline $\mathrm{T}=75^{\circ} \mathrm{C}$ & 11.09 & 178 & 1636 & 9790 & 16.05 & 9.19 & 5.98 & & & \\
\hline $\mathrm{T}=125^{\circ} \mathrm{C}$ & 8.77 & 141 & 1215 & 7750 & 16.08 & 8.62 & 6.38 & & & \\
\hline $\mathrm{T}=175^{\circ} \mathrm{C}$ & 7.75 & 124 & 1074 & 6850 & 16.00 & 8.66 & 6.38 & & & \\
\hline $\mathrm{T}=75^{\circ} \mathrm{C}$ & 20.01 & 327 & 2777 & 17845 & 16.34 & 8.49 & 6.43 & & & \\
\hline $\mathrm{T}=125^{\circ} \mathrm{C}$ & 16.12 & 261 & 2234 & 14295 & 16.19 & 8.56 & 6.40 & & & \\
\hline $\mathrm{T}=175^{\circ} \mathrm{C}$ & 14.38 & 232 & 1993 & 12740 & 16.13 & 8.59 & 6.39 & & & \\
\hline
\end{tabular}
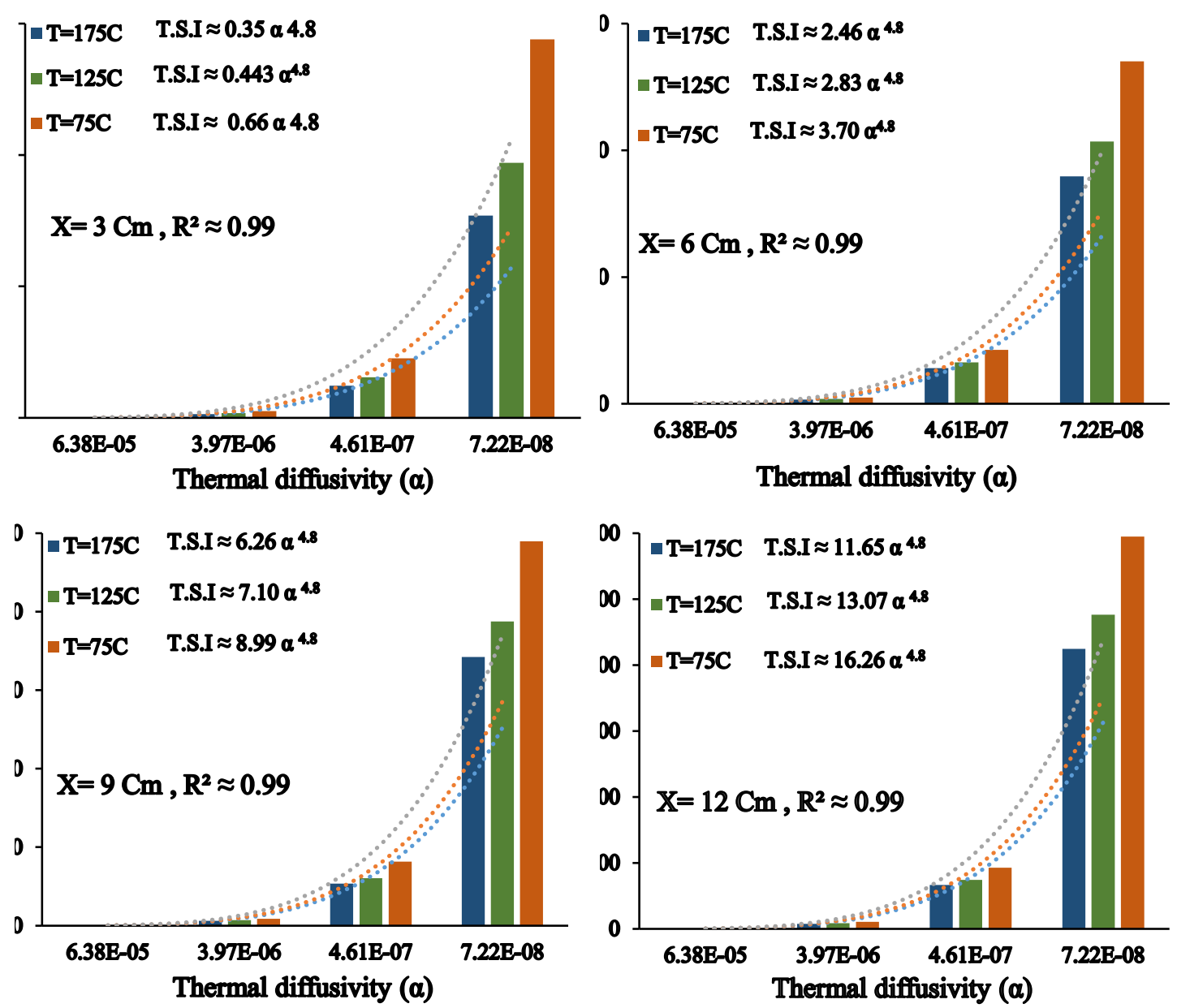

Figure 5. relationship between thermal diffusivity and thermal sensitivity inception

Figure 5 shows the effect of thermal diffusivity on Thermal sensitivity inception (T. S.I).

In the figure, thermal diffusivity impact is very little on the Thermal sensitivity inception (T. S.I) at the points near the hot side, and this effect increases by moving away from the hot side. 
We also note that increasing the temperature of the hot side reduces the Thermal sensitivity inception (T.S.I)

From the curves in figure 5. In addition, depending on the Excel program was obtained a number of mathematical equations express a power relationship, can be conceptualized in the following general relationship.

$$
\text { T.S.I (sec. }) \cong C * \alpha^{n} \quad \ldots \ldots(3)
$$

The exponent value (n) was very close to (4.8), while the value of $(\mathrm{C})$ ranged between 16.26).

\section{4- Conclusions}

1. The time of thermal sensitivity inception (T.S.I) will increases with decreasing the thermal diffusivity, When other variables are constant. Where the rate of increment up to 900 times between the highest and the lowest thermal diffusivity.

2. The hot side temperature has inversely effect on the time of thermal sensitivity inception (T.S.I). Where the increment percentage in (T.S.I) about $87 \%$ when the hot side temperature decrease from $175^{\circ} \mathrm{C}$ to $75^{\circ} \mathrm{C}$ when the distance $3 \mathrm{~cm}$ from the hot side. but this increment in (T.S.I) decrease by moving away from the hot side to reach $40 \%$ at distance $12 \mathrm{~cm}$ from the hot side.

3. Relationship between the amounts of distance from the hot side with the Thermal sensitivity inception (T.S.I) is positive.

4. Thermal diffusivity has an influence on the Thermal sensitivity inception (T. S.I) much more than the rest of the variables such as distance from the hot side and its temperature.

5. Two equations has been derived to calculate the Thermal sensitivity inception (T.S.I) for any solid material with a known thermal diffusivity depending on the thermal data of any other material.

\section{CONFLICT OF INTERESTS.}

- There are no conflicts of interest.

\section{References}

[1] Ridha Hameed Mageed, "Effect of Temperature Difference on the Steady State Time Using ANSYS". Journal of University of Babylon for Engineering Sciences, Vol. (26), No. (8): 2018.

[2] Mohsin Obaid Muhi,"Numerical Evaluating Study of the Thermal Initiation Time of Sample Affected by Applied Thermal load". Journal of University of Babylon for Engineering Sciences, Vol. (26), No. (8): 2018.

$$
\begin{aligned}
& \text { [3] رضا حميد مجيد، دراسة تأثثر الانتشارية على توزيع درجات الحرارة غير المستقرة خلال الجدران ذات التوصبل الحراري } \\
& \text { المنخفض مجلة جامعة بابل/ العلوم الصرفة والتطبيقية و العلوم الهندية، المجلد 26، العدد (1)، } 2018
\end{aligned}
$$

[4] Vebil Yildırım, "Exact Thermal Analysis of Functionally Graded Cylindrical and Spherical Vessels". International Journal of Engineering \& Applied Sciences (IJEAS), Vol.9, Issue 2 Pages 112-126, 2017.

[5] M. Norouzi \& H. Rahmani, "An exact analysis for transient anisotropic heat conduction in truncated composite conical shells". Applied Thermal Engineering, Volume 124, Pages 422-431, 2017

[6] Mahmood Norouzi \& Hossein Rahmani, A general exact analytical solution for anisotropic nonaxisymmetric heat conduction in composite cylindrical shells. International Journal of Heat and Mass Transfer, Volume 93, Pages 41-56, 2016.

[7] Liangxian Gu, Yifan Wang, Shengbo Shi \& Cunxi Dai, An approximate analytical method for nonlinear transient heat transfer through a metallic thermal protection system. International Journal of Heat and Mass Transfer, Volume 103, Pages 582-593, 2016.

[8] Nitin J. Wange, M. N. Gaikwad \& S. P. Pawar, "Analytical Solution for Three-Dimensional Unsteady Heat Conduction in a Multilayer Cylinder with Volumetric Heat Source". International Journal of 
Advanced Engineering, Management and Science (IJAEMS), https://dx.doi.org/10.24001.71 ISSN : 2454-1311, 2017.

[9] Mohammad Hossein Bazyar \& Abbas Talebi, "Scaled boundary finite-element method for solving non-homogeneous anisotropic heat conduction problems". Applied Mathematical Modelling, Volume 39, Issues 23-24, Pages 7583-7599, 2015.

[10] Ru- Li Lin, "Explicit full field analytic solutions for two-dimensional heat conduction problems with finite dimensions". International Journal of Heat and Mass Transfer, Volume 53, Issues 9-10, Pages 1882-1892, 2010.

[11] Chen An \& Jian Su., "Lumped models for transient thermal analysis of multilayered composite pipeline with active heating". Applied Thermal Engineering, Volume 87, Pages 749-759, 2015.

[12] Darius Pupeikis, Vytautas Stankevičius \& Arūnas Burlingis, "THE EFFECT OF THE FOURIER NUMBER ON CALCULATION OF AN UNSTEADY HEAT TRANSFER OF BUILDING WALLS". JOURNAL OF CIVIL ENGINEERING AND MANAGEMENT, Volume 16- Issue 2, Pages 298-305, 2010

[13] Filippo de Monte, James V. Beck \& Donald E. Amos, "Solving two-dimensional Cartesian unsteady heat conduction problems for small values of the time". International Journal of Thermal Sciences, Volume 60, Pages 106-113, 2012.

[14] A. Amiri Delouei, M. H. Kayhani \& M. Norouzi, "Exact analytical solution of unsteady axisymmetric conductive heat transfer in cylindrical orthotropic composite laminates". International Journal of Heat and Mass Transfer, Volume 55, Issues 15-16, Pages 4427-4436, 2012.

[15] RASEELO J MOITSHEKI and CHARIS HARLEY, "Transient heat transfer in longitudinal fins of various profiles with temperature-dependent thermal conductivity and heat transfer coefficient". Pramana-J. Phys., Vol. 77, No. 3, 2011.

[16] YuzhiSunIndrek S.Wichman, "On transient heat conduction in a one-dimensional composite slab". International Journal of Heat and Mass Transfer, Volume 47, Issues 6-7, Pages 1555-1559, 2004.

[17] Canale R., Chapra S. ,Numerical Methods for Engineers .Third ed.,McGraw-Hill, New York, NY, 1998.

[18] Apache-Tables User Guide. IES Virtual Environment. http://www.iesve.com/downloads/help/ VE2015/VirtualEnvironment.pdf.

[19] APPENDIX-1,.PROPERTY TABLES AND CHARTS (SI UNITS). http://cecs.wright.edu / sthomas/htappendix01.pdf. 


\section{تأثير اختلاف درجة الحرارة بين نهايتي عينة على بلء التحس الحراري \\ رضا حميد مجيد \\ قسم الثقنيات الميكانيكية، الدعهُ الثقني كربلاء، جامعة الفرات الأوسط الثقنية، 56001، كربلاء، العراق}

\section{inkr.red@atu.edu.iq}

تعرضت هذا البحث لاراسة تأثير الفرق بين درجتي حرارة نهايتي جسم معرض لإجهاد حراري في الحالة غير المستقرة

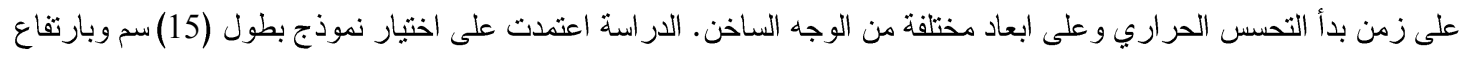

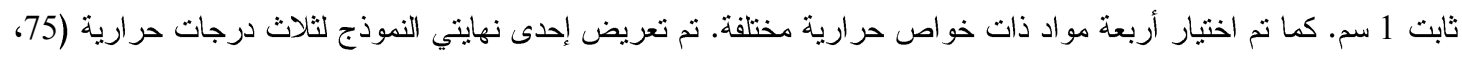

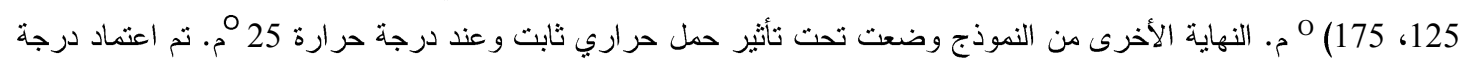

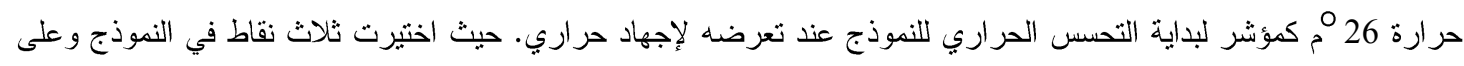

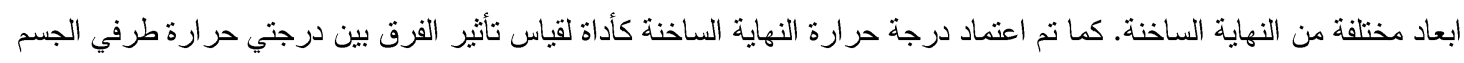

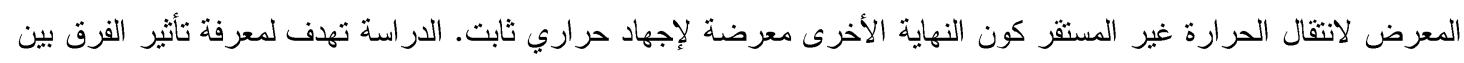

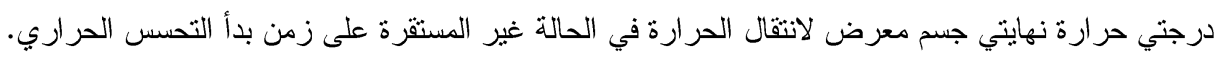

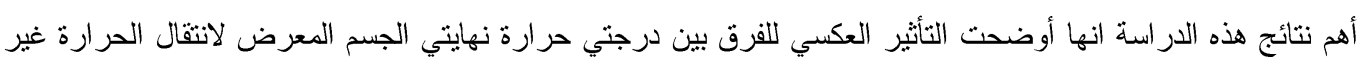

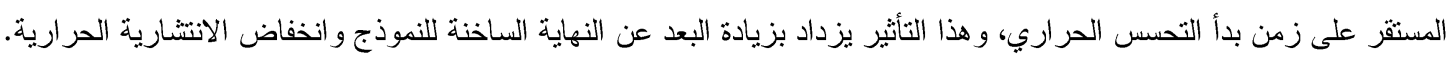

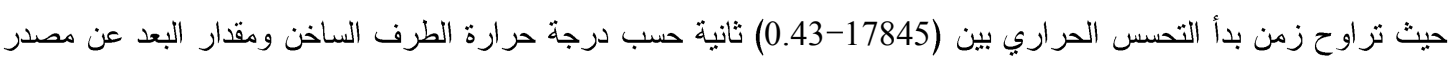
التنخين ومقدار الانتثارية الحر ارية للنموذج لكل حالة. (الكلمات الدالة: انتقال الحر ارة غير المستقرة، بدأ التحسس الحراري (T.S.I)، الانتثارية الحرارية (م)، درجة حر ارة الطرف الساخن (T) (T) ( 